\title{
DEVELOPMENT OF ECO FRIENDLY FEMININE HYGIENE PRODUCT
}

\section{T.R. INDUMATHI ${ }^{1} \&$ DR. DIVYA.R ${ }^{2}$}

${ }^{I}$ Assistant Professor, Department of Costume design and Fashion, Dr. N.G.P. Arts and Science College, Coimbatore.

${ }^{2}$ Assistant Professor, Department of Costume design and Fashion, PSG College of arts and Science, Coimbatore

\begin{abstract}
Medical textiles are a major growth area within the technical textiles sector and the use of textiles in medicine has a long tradition, but now applied vitally in the field of health care and hygiene. Hygiene has become the significance on textiles as they are termed as the 'second skin' and are closest to the human body. Women are highly infected during their menstrual time, due to unhygienic practices during menstruation, microorganism, unaware of hygiene products, etc. This leads to allergies, irritation, urinary tract infection, vaginal infections, and high risks as infertility and cervical cancer. Using sanitary napkin during menstruation is the hygiene method of menstrual protection. But commercial napkins with its typically disclosed ingredients indicating the pad may contain non-biodegradable synthetic fibers, petrochemical additives, etc. In this research, to make feminine product more protective and as medical equipment for treatment, an effort was made to develop menstrual hygiene product, 'Non-toxic herbal sanitary napkin' with the natural plant fibers and finished with Abutilon Indicum and Sennaauriculataherbal composite extract having various properties like antimicrobial, anti-itching, anti-allergic, odour control, wound-healing, coolness etc.
\end{abstract}

KEYWORDS: Menstruation, Non-Toxic, Antimicrobial, Abutilon Indicum, Sennaauriculata, Anti-Allergic

Received: Jun 06, 2020; Accepted: Jun 26, 2020; Published: Jul 23, 2020; Paper Id.: IJMPERDJUN2020425

\section{INTRODUCTION}

A textile is a malleable material consisting of a system of natural and artificial fibers. These are produced either by weaving, knitting or nonwoven methods. The technical textiles are the materials and products manufactured primarily for their functional performance. In this sector medical textiles are the developing area within the range of applications as such products continue to grow and increase with every new expansion ${ }^{(1)}$. The use of textiles in medicine has a long tradition but now applied vitally in the field of health care and hygiene. Health care and hygiene textiles consist of absorbent disposable products, such as sanitary napkins, nappy pads, tampons, incontinence products, panty liners and wipes which are mostly designed to receive, absorb and retain body fluids ${ }^{(2)}$.

Women are highly infected during their menstrual time. This is due tounhygienic practices during menstruation, unaware of hygiene products, the microorganism which highly affects moist skin, grows highly in moderate body temperature, etc. This leads to allergies, irritation, urinary tract infection, vaginal infections, and high risks as infertility and cervical cancer. Using sanitary napkin during menstruation is the hygiene method of menstrual protection. Sanitary napkin is an absorbent item which is worn outside the body by women in case of vaginal surgery recovery, menstruation and post birth bleeding, etc.

Among these, development of antimicrobial textile finish is also highly necessary, since textiles are in direct contact with human body. The textile products that are particularly made from natural fibers like cotton, 
viscose, etc. have a serious problem of microorganism because of their surface area and ability to maintain moisture $^{(3)}$.Finishing of fabrics in an eco-friendly manner is getting very radical these days. Coating of bioactive plant extract on to fabrics is an emerging technology in the production of medical textiles, as various properties like antimicrobial, fragrance, anti-allergic, anti-septic, and wound-healing etc. can be incorporated in the fabric by the application of herbal extracts ${ }^{(4)}$.

Therefore, in this study, an effort is made to explore the possibility of the herbal finishing on natural fiber fabric made with cotton and viscose. The medicinal properties of herbs can be incorporated in a fabric by the process of dyeing, finishing, micro-encapsulation, etc. The attempts have been made to develop medicinal herb extract treated textiles using alternate medicinal concepts to cure several diseases. ${ }^{(6,7)}$.

\section{METERIALS AND METHODS}

\section{Selection of Fibers}

The fibers for designing of sanitary napkin are cotton, viscose, corn pith and cassava starch selected because of the following reasons.

\section{Cotton}

Absorbent cotton also known as surgical cotton or cotton wool is mainly used for medical purposes. The absorbent cotton fibers are more elastic, which has the diameter of $16.30 \mathrm{~mm}$, and a length of $12-40 \mathrm{~mm}$. The raw cotton is hydro-phallic in character and free from external impurities to be fit for use in surgical dressings and personal hygiene.

\section{Viscose}

Regenerated viscose fiber is very similar to cotton, as they are made from cellulose based fibers that originate from wood pulp. A pure viscose fiber with staple length, high luster and moisture absorbency property were selected for the fabric formation.

\section{Manihot Esculenta}

Tapioca plant grown at the region of innermost Tamil Nadu is selected for this study. The root called cassava is harvested at fully matured stage, identified for disease free plant part.

\section{Fabrication Process}

\section{Cotton Lap}

Surgi cotton brand product is selected with 300gms net weight and purchased for the sanitary napkin core development which was chemically inert and soft to give maximum liquid absorption and protection.

\section{Nonwoven Viscose Fabric}

Fine viscose nonwoven fabric with the GSM of 300, made with spun lace technique is selected. The fabric texture is soft, flexible, light weight and white in colour. It is selected for its highly disposable and degradable nature. Some physical tests were undergone for the nonwoven viscose fabric for its functional property for sanitary napkins, as on top layer and emollient layers for Antibacterial test, wicking test, and air permeability tests in standard methods. 


\section{Manihot Esculenta Film}

The bottom (hydrophobic) layer of the sanitary napkin is made from the plant fiber material Cassava starch particles converted to thin, transparent and odorless film.. It is an alternative product for plastic films/ sheets

\section{Selection of Herbs}

The medicinal herbs and its finishing on fabric ensure permanent effectiveness and compatibility to the human skin.

\section{Collection of Medicinal Herb}

Abutilon Indicum: The plant require for the study were collected from the interior villages of Coimbatore, which are grown under optimal environmental condition. The leaves are fresh and disease free, identified as dark green colour with heart shaped.

SennaAuriculata (Tanner's Cassia): The plant require for the study were collected from the interior villages of Coimbatore, which are grown under optimal environmental condition. The Flowers are fresh and disease free, identified as bright yellow in colour. The herbs are selected for their potential properties studied under the reviews of literature.

\section{Herbal Extraction Procedure}

Abutilon Indicum: The collected herb Abutilon Indicum (leaves) were shadow dried within a temperature range of $37-40^{\circ} \mathrm{C}$. After drying the grinding was carried out to breakdown the leaves of the plant into fine powder. Antibacterial active substances were extracted from the plant by aqueous extraction method, by adding $20 \mathrm{~g}$ of herbal powder in $100 \mathrm{ml}$ of water for $24 \mathrm{hrs}$.

SennaAuriculata: The collected flowers of were shadow dried within a temperature range of 37-40 C. After drying, grinding was carried out to breakdown the flowers of the plant into fine powder.The active substances were extracted from the flower powder by aqueous extraction method, by adding $20 \mathrm{~g}$ of herbal powder in $100 \mathrm{ml}$ of water for 24 hrs.

\section{Herbal Extraction Composite Preparation Procedure}

The selected herbs were extracted with aqueous and make as composite with the equal ratio of 1:1 that was $20 \mathrm{ml}$ each for $200 \mathrm{gms}$ of viscose fabric.

\section{Method of Herbal Finishing on Fabric}

\section{Imparting Herbal Finish to the Selected Fabric}

The viscose fabric samples were treated with herbal composite extract using citric acid as cross-linking agent, applied onto the fabrics by pad-dry-cure method with material- to liquor ratio of $1: 20$ at $50^{\circ} \mathrm{C}$ using $8 \%$ citric acid concentration. After padding for $30 \mathrm{~min}$, the samples were taken and dried at $100-120^{\circ} \mathrm{C}$ for $5 \mathrm{~min}$ and cured at $180^{\circ} \mathrm{C}$ for $3 \mathrm{~min}$. 


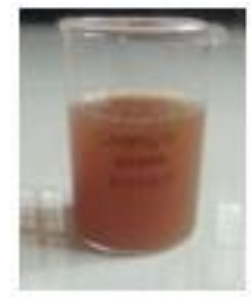

(a)

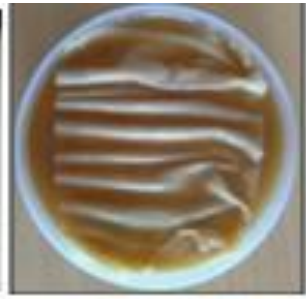

(b)

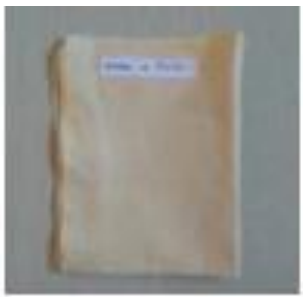

(c)

Plates 3 (a): Composite Herbal Extract (b): Fabric Dipped in Herbal Extract, (c): Herbal Finished Viscose Fabric.

\section{Objective Evaluation}

\section{Antibacterial Assessment of Herbal Finished Fabric}

The fabrics non-woven viscose finished with composite extract were analyzed for their antibacterial testing using the standard AATCC - 147 test method (parallel streak method) against test organisms of gram positive organism (staphylococcus aureus) and gram negative organism (Escherichia coli). This method is follow to test the ability of the treated textile to inhibit the growth of microorganisms, to be bacteriostatic. It allows you to estimate the activity and efficacy of the herbal finish on microorganisms.

\section{Inoculation of Herbal Treated Specimen}

Test specimens (fabrics) were cut into pieces $(25 \mathrm{~mm} * 50 \mathrm{~mm})$. A $50 \mathrm{~mm}$ length permits the specimen to lay across parallel inoculums steaks each of diminishing width from both $8 \mathrm{~mm}$ to $4 \mathrm{~mm}$ wide. Sterile ATCC bacteriostatic agar plates were prepared. Using sterile 4mm inoculating loop, one loop full of culture (E.Coli ATCC 25922 and S.Aureus ATCC 6538) was loaded and transferred to the surface of the agar plate by making five parallel streaks.

\section{Measuring the Zone of Inhibition}

Most of the human pathogens grow at $37^{\circ} \mathrm{C}$. The culture media after inoculation is incubated at $37^{\circ} \mathrm{C}$ for $18-24$ hours. The inoculated plates were examined for the interruption of growth along the streaks of inoculum beneath the fabric for a clear zone of inhibition beyond the fabric edge. The average width of the zone of inhibition around the test specimen calculated in $\mathrm{mm}$.

\section{Design and Development of Product}

\section{Materials Used}

The materials used for the product development are obtained completely from natural by-products such as cotton, viscose, Esculenta starch, etc. The major structural components

\section{Procedure for Design and Development of Product}

In this research we have developed a durable product improved with its hygiene management.

Top layer: The nonwoven spunlace fabric construction with $0.6 \mathrm{gms}$, made by fine viscose fibers, produced with hydrophilic formulation, facing towards the skin absorbs the fluid evenly and dries quickly acts as skin contact layer. 
Emollient layer: this second layer is fabricated with $0.8 \mathrm{gms}$, same as first layer and finished with the medicinal herbal composite extract. It is a soft fabric layer with antimicrobial property treats skin disorders and avoids infections. It also reduces the undesirable smell during menstruation

Absorbent core: it is a liquid absorbing surgical cotton material formed typically as a carded web, with $9.2 \mathrm{gms}$, which helps in absorption and spreading of fluid all over the napkin, which are set as centered material with thickness of $3 \mathrm{~mm}$.

Bottom layer: It is a hydrophobic layer which helps in preventing leakage of fluid outside the absorbent pad with $1.4 \mathrm{gms}$ of weight. It is a soft, smooth film of thickness $0.05 \mathrm{~mm}$. As a fluid repellent material this layer faces towards the garment side, sticks with the help of adhesive which was protected with release paper.

Finally the top and the bottom layer are sealed tightly through wet bonding with the emollient and absorbent core layer at center as it will not move during strenuous activities.

\section{Evaluation of Final Product}

\section{Liquid Strike through Time Test (EDNA 150.5 \& ISO 9073-8)}

The test carried out using a modified method of EDANA 150.5-02 standard method (Shanmugasundram 2010). A drop of artificial blood solution was allowed to fall on the napkin test swatch and the time taken for the solution to transport from the upper layer to the inner layer of the napkin sample was calculated. This was measured by observing the drop closely such that dull wet spot was seen on the wet area of the sample. All the samples were conditioned for 24 hours before the tests (plate 29). The results are tabulated in Table.18.

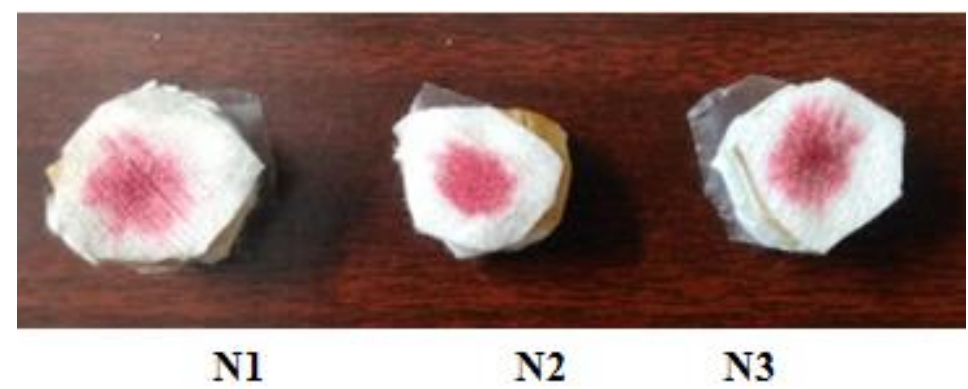

Figure 1: Time in Seconds Recorded After Drop Test in Each Napkin Samples (N=3).

\section{Subjective Evaluation}

\section{Cytotoxity Test}

The cytotoxicity test is one of the biological evaluation and screening tests that use tissue cells to observe the cell growth, reproduction and morphological effects by medical constituents. It is preferred as a pilot project test and an important indicator for toxicity evaluation have high sensitivity.

An in vitro Cytotoxic test method was performed for the given test sample as per ISO 10993:5. The culture medium from the L929 cells was replaced with fresh medium. Culture MEM medium supplemented with fetal bovine serum was used. Test samples in triplicates were added on the cells. After incubation at $37^{\circ} \mathrm{c}$ for 18 hours, MTT $(1 \mathrm{mg} / \mathrm{ml})$ were added in all the wells and incubated for 4 hours. After incubation, DMSO were added in the wells and read at 570mm using photometer. Cytotoxity and cell viability were calculated by below formula. 


$$
\begin{gathered}
\text { Cytotoxity }=[(\text { Control-Treated }) / \text { Control }] * 100 \\
\text { Cell viability }=(\text { Treated } / \text { Control }) * 100
\end{gathered}
$$

Table 1: Cell Viability Calculation for Observation

\begin{tabular}{|c|c|l|}
\hline S.NO & GRADE $(\boldsymbol{\%})$ & REACTIVITY \\
\hline 1 & 0 & NONE \\
\hline 2 & $1-20$ & SLIGHT \\
\hline 3 & $21-50$ & MILD \\
\hline 4 & $51-70$ & MODERATE \\
\hline 5 & $>71$ & SEVERE \\
\hline
\end{tabular}

\section{RESULTS AND DISCUSSIONS}

Objective Evaluation of Viscose Fabric

Assessment of Antibacterial Activity of Viscose Fabric

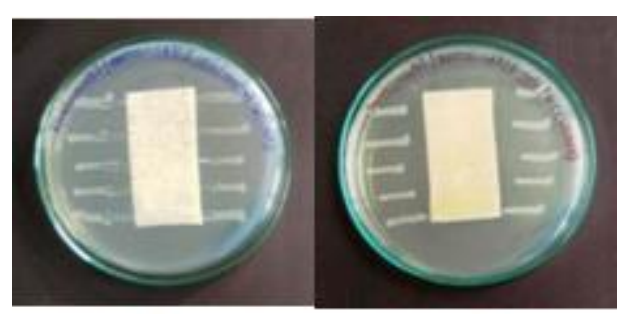

A

B

Plates 1: Influence of Bacteria Escherichia Coli (ATCC 25922) on Control (A), Finished (B) Fabrics.

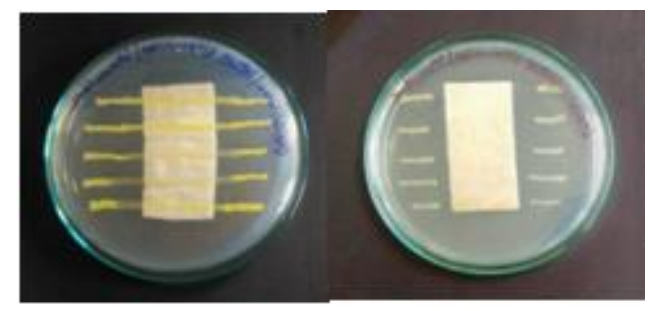

A

B

Plates 2: Influence of Bacteria Staphylococcus Aureus (ATCC 6538) on Control (A), Finished (B) Fabrics.

Table 2: Assessment of Qualitative Antibacterial Activity of Viscose Fabric Finished with Herbal Extracts (AATCC-30 TEST METHOD)

\begin{tabular}{|c|l|c|c|}
\hline S.NO & \multicolumn{1}{|c|}{ FABRICS } & \multicolumn{2}{c|}{ ANTIBACTERIAL } \\
\hline & $\begin{array}{l}\text { VISCOSE } \\
\text { (NON WOVEN) }\end{array}$ & $\begin{array}{l}\text { Escherichia coli } \\
\text { ATCC 25922 }\end{array}$ & $\begin{array}{l}\text { Staphylococcus aureus } \\
\text { ATCC 6538 }\end{array}$ \\
\hline 1 & CONTROL & Nil & Nil \\
\hline 2 & HERBAL FINISHED & 32.2 & 30.8 \\
\hline
\end{tabular}

Table shows that viscose nonwoven fabric sample finished with composite herbal extract shows excellent antibacterial activity. Gram negative bacteria (Escherichia coli) shows better result than gram positive bacteria (Staphylococcus aureus). 


\section{Assessment of Antibacterial Activity for Selected Fabric by Parallel Streek Method}

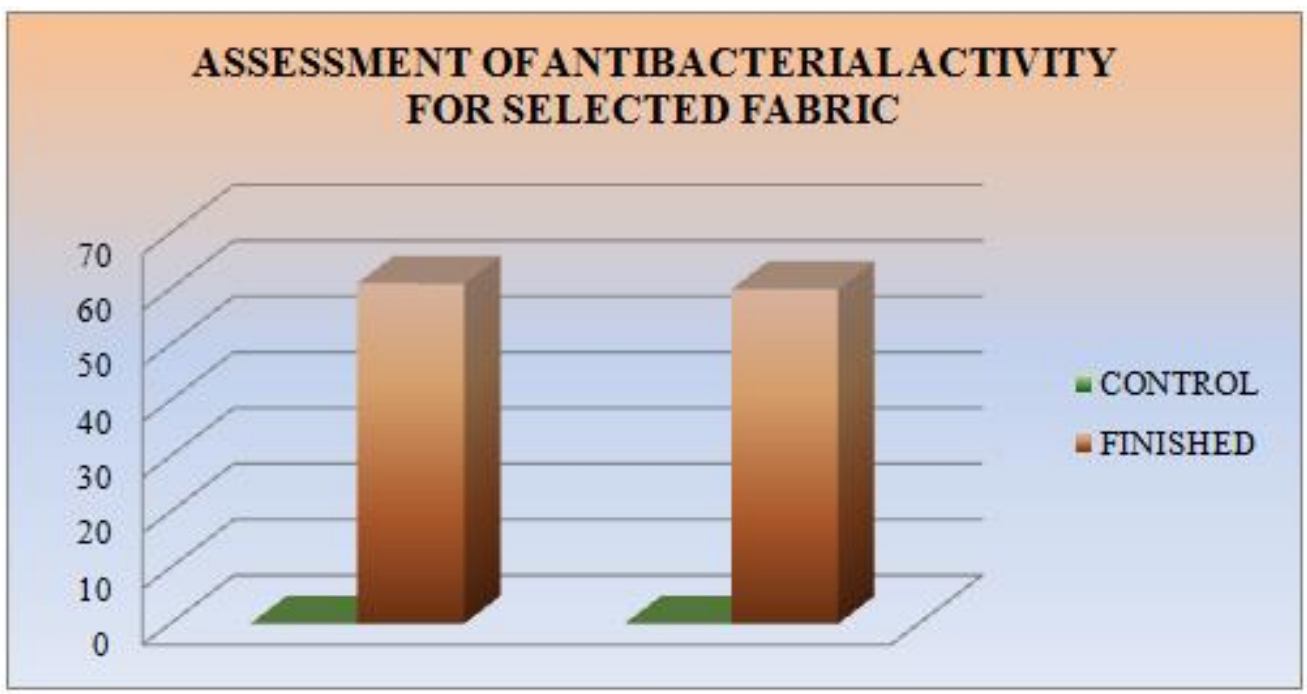

Figure 2: Assessment of Antibacterial Activity of Viscose Fabric.

The result shows that the emollient layer of the product have excellent antibacterial activity against the Gram negative bacteria (Escherichia coli) and gram positive bacteria (Staphylococcus aureus).

\section{Evaluation of Developed Product}

Table 3: Liquid Strike through Time (ISO: 9073-8)

\begin{tabular}{|c|c|c|c|}
\hline S. No. & Napkin Test Swatch & Time (s) & t-Value \\
\hline 1 & $\mathrm{~N}_{1}$ & 1.2 & \multirow{2}{*}{0.03} \\
\hline 2 & $\mathrm{~N}_{2}$ & 1.6 & \multirow{2}{*}{0.5} \\
\cline { 1 - 3 } 3 & $\mathrm{~N}_{3}$ & $\mathbf{1 . 4} \pm \mathbf{0 . 3}$ & \\
\hline \multicolumn{2}{|c|}{ Mean Time (S) } &
\end{tabular}

The test values obtained are shown in the table 20. In which the test specimens contacted with the drop of blood solution transports quickly to the next layers of the napkin was calculated. It also shows that the top layer dries quickly analyzed by the dull spot of blood drop on it. The compared sample obtained 0.03 as significant T- value.

Thus the fully developed end product was evaluated by standard IS: 5405-1980 testing methods. In which the results mean value and t-value calculations show's that the product herbal sanitary napkin compiles with medical standards and meets all the requirements of these parameters like absorbency, retention, $\mathrm{pH}$, etc., for feminine usage, and can competes among market products.

\section{Subjective Evaluation}

In Vitro Cytotoxity Test (Direct Method) ISO 10993-5

Table 4: Observation of Cytotoxity on Cell Line

\begin{tabular}{|c|c|c|c|c|}
\hline \multirow{2}{*}{ SAMPLE } & SAMPLE PARTICULAR & $\begin{array}{c}\text { CYTOTOXITY } \\
(\boldsymbol{\%})\end{array}$ & $\begin{array}{c}\text { CELL VIABILITY } \\
(\boldsymbol{\%})\end{array}$ & $\begin{array}{c}\text { CYTOTOXIC } \\
\text { REACTIVITY }\end{array}$ \\
\hline 1 & Herbal Sanitary Napkin & 0 & $>99$ & NONE \\
\hline
\end{tabular}

As per ISO 10993:5 the test sample herbal sanitary napkin showed none cytotoxic reaction on L929 cells after 24 hours contact. Control gave none cytotoxic reactivity as expected. The cell line L929 showed healthy viable consequence on established product. 


\section{CONCLUSIONS}

Consumer experiences of disposable hygiene products designed and developed expensively by the manmade elements in market are replaced by the natural agricultural by products and wastes are focused in this study pertained good result. The antimicrobial and anti odour finish highlights the product from the herbal component potentials as avoiding infections during menstruation. Its quality satisfies the users, gives them comfort as skin friendly and stress free zone during menstrual time. These chemical free napkins decomposed in soil after the usage, are converted to manure in few days. It also, will not produce hazardous gasses while burning it, results in ash. Thus this act will reduce the landfills and the product gives excellent care on health and environment. Natural materials in this product are playing major role through its diversified applications and undoubtedly the future of this hygiene textile product will appear to be bright and the demand for cost saving with high performance product will fulfill by this research work on herbal Ecofriendly sanitary napkin.

\section{REFERENCES}

1. Russell, S.J. 2007, “Handbook of nonwovens”, Woodhead Publishing Limited Cambridge, England.

2. Parveenbanu K, Pradeepa P “ Non Implantable Materials in Medical Textiles” International Journal of Current Research,vol 6: 2014, pp.61-20.

3. Thilagavathi $G$ et al, "Development of eco-friendly antimicrobial textile finishes using Herbs", Indian Journal of Fiber \& Textile Research, vol.30, 2005, pp. 431-436.

4. Roshan Paul, "Improving comfort, performance and protection" FuncionalFnishes for Textiles, Woodhead Publishing Series in Textiles No.156, 2015.

5. Priyanka Tripathi,N.S. Chauhan \& J.R. Patel “Anti-inflammatory activity of Abutilon indicum extract"Natural Product Research, Volume 26, Issue 17, Pages 1659-1661, 14 Oct 2011.

6. Muhit Md. Abdul et al. "Cytotoxic and Antimicrobial Activity of the Crude Extract of Abutilon Indicum"International Journal of Pharmacology and Phytochemical Research, 2010; vol. 2(1); pp.1-4.

7. P.Saratha and Dr. U. Anitha Devi “Medicinal properties of Telangana state flower (cassia auriculata Linn)” World journal of pharamaceutical research, volume 6, issue 8, 1597-1605

8. SuneelaGarg et al., "Mensuration Related Myths in India: Strategies for Combating It", Journal of Family Medicine and Primary Care, September 28,2016, ip:88.80.49.246.

9. Patil, Ravindragouda, G. Jeyasekaran, and S A Shanmugam. "Antimicrobial Potential of Marine Actinomycetes Isolated from Mangrove Swamp Areas." IMPACT: International Journal of Research in Applied, Natural and Social Sciences (IMPACT: IJRANSS) 4.7 (2016):119-126.

10. Manhas, Sarika, Sabiya Asmat, and Tashi Dolker. "Knowledge about Menarche and Menstruation, Among Tribal Females of Kargil." International Journal of Agricultural Science and Research (IJASR) 7.5 (2017):605- 612.

11. Aishwariya, S. "Observations on Recycling Techniques for Textiles-A Review." International Journal of Textile and Fashion Technology (IJTFT) 8.4 (2018):19-24. 